\title{
Obstetrics and Gynecology
}

\section{Preterm Birth in Nulliparous Women}

\author{
Roziya K. Kuzibaeva; Valery G. Volkov, PhD, ScD* \\ Tula State University, Tula, the Russian Federation
}

\begin{abstract}
The aim of this study was to assess the frequency and risk factors of Preterm birth (PB), depending on the mechanism of their occurrence in nulliparous women with singleton pregnancies.

Methods and Results: This retrospective, population-based cohort study included 327 nulliparous women who gave birth at 22-37 weeks gestation. Three groups of women were formed: Group 1 included 32 women with spontaneous PB, Group 2 included 115 women with preterm premature rupture of membranes (PROM), and Group 3 included 180 women with medical indication for PB. The average age of the mothers for the whole group was $29.3 \pm 6.0$ years. Depending on the gestational age, PB in 22-27 weeks occurred in 23(7.4\%) cases, 28-33 weeks in 110(33.6\%) cases, and 34-37 weeks in 194(59\%) cases. In our cohort, the frequency of PB resulting from spontaneous PB, PROM or medical indication for PB was $9.8 \%, 35.2 \%$, and 55\%, respectively. The main risk factors for PB were preeclampsia of varying severity, placental abruption, placental insufficiency, and fetal growth retardation. The highest number of pregnancy complications was found in Group 3.

Conclusion: PB in nulliparous women occurs more often in the period of 34-37 weeks, the main reason being medical indications (maternal or fetal). Attempts to analyze, interpret, and reduce the level of PB should be considered separately, depending on the mechanism of their occurrence.(International Journal of Biomedicine. 2021;11(1):39-41.)
\end{abstract}

Key Words: preterm birth $\bullet$ nulliparity $\bullet$ risk factor $\bullet$ preterm premature rupture of membranes $\bullet$ preeclampsia

For citation: Kuzibaeva RK, Volkov VG. Preterm Birth in Nulliparous Women. International Journal of Biomedicine. 2021;11(1):39-41. doi:10.21103/Article11(1)_OA7

\section{Introduction}

Preterm birth $(\mathrm{PB})$ is one of the medical and social problems that are relevant for most countries. ${ }^{(1,2)}$ A nationwide retrospective study found that nulliparity was independently associated with an overall increased risk of spontaneous PB, compared to women during their second pregnancy. ${ }^{(3)}$

The effectiveness of $\mathrm{PB}$ prevention is low, despite a large number of scientific studies in this area. Early diagnosis and accurate prediction of PB and perinatal outcomes are not possible due to the large number of etiological factors and the lack of a specific diagnostic method. ${ }^{(4,5)} \mathrm{PB}$ is a complex syndrome with several obstetric precursors, including spontaneous $\mathrm{PB}$ with intact membranes, preterm premature rupture of membranes (PROM) with subsequent $\mathrm{PB}$, and indicated or iatrogenic PB. ${ }^{(6,7)}$

*Corresponding author: Prof. Valery G.Volkov, PhD, ScD. Tula State University, Tula, Russia.E-mail:valvol@yandex.ru
The division of PB into different subtypes is important both from a clinical and epidemiological point of view, since the etiology and prevention strategies for each of them differ.

The aim of this study was to assess the frequency and risk factors of $\mathrm{PB}$, depending on the mechanism of their occurrence in nulliparous women.

\section{Materials and Methods}

This retrospective, population-based cohort study included nulliparous women who gave birth in the Tula Regional Perinatal Center at 22-37 weeks gestation from January 1, 2014 to December 31, 2014. The study included 327 women.

Inclusion criteria were first birth, for which the date of the last menstruation is known, confirmed gestational age, and singleton pregnancy. Exclusion criteria were multiple pregnancies and repeated births.

This study was approved by the Ethics Committee of Tula State University. 
PB was classified into three clinical subtypes: spontaneous PB with intact fetal membranes, PROM before onset of labor, and indicated preterm birth. Thus, three groups of women were formed: Group 1 included 32 women with spontaneous PB, Group 2 included 115 women with PROM, and Group 3 included 180 women with medical indication for PB. ${ }^{(8)}$

The information relating to the $\mathrm{PB}$ subtypes was abstracted from the medical record.

Statistical analysis was performed using the Statistica 6.1 software package (Stat-Soft Inc., USA). Group comparisons with respect to categorical variables were performed using chi-square test. A probability value of $P<0.05$ was considered statistically significant.

\section{Results and Discussion}

The average age of the mothers for the whole group was $29.3 \pm 6.0$ years. Depending on the gestational age, PB in 22-27 weeks occurred in 23(7.4\%) cases, $28-33$ weeks in $110(33.6 \%)$ cases, and 34-37 weeks in 194(59\%) cases. In our cohort, the frequency of $\mathrm{PB}$ resulting from spontaneous $\mathrm{PB}$, PROM or medical indication for PB was $9.8 \%, 35.2 \%$, and $55 \%$, respectively.

The effect of diseases on the outcome of pregnancy is presented in Table 1. In Group 3, the leading risk factor for PB was pre-existing hypertension.

Table 1.

Diseases of pregnant women, $n(\%)$

\begin{tabular}{|l|c|c|c|c|}
\hline \multicolumn{1}{|c|}{ Variable } & $\begin{array}{c}\text { Ggroup 1 } \\
(\mathrm{n}=32)\end{array}$ & $\begin{array}{c}\text { Group 2 } \\
(\mathrm{n}=115)\end{array}$ & $\begin{array}{c}\text { Group 3 } \\
(\mathrm{n}=180)\end{array}$ & Statistics \\
\hline Anemia & $7(21.8)$ & $27(23.5)$ & $41(22.8)$ & $\begin{array}{l}\chi 2=0.042 \\
P=0.9702\end{array}$ \\
\hline Kidney diseases & $3(9.3)$ & $11(9.6)$ & $30(16.7)$ & $\begin{array}{l}\chi 2=3.546 \\
P=0.1698\end{array}$ \\
\hline $\begin{array}{l}\text { Pre-existing } \\
\text { hypertension }\end{array}$ & $1(3.1)$ & $9(7.8)$ & $41(22.8)$ & $\begin{array}{c}\chi 2=16.107 \\
P=0.0003\end{array}$ \\
\hline Diabetes mellitus & $1(3.1)$ & $4(3.5)$ & $12(6.7)$ & $\begin{array}{l}\chi 2=1.757 \\
P=0.4154\end{array}$ \\
\hline Myopia & $1(3.1)$ & $4(3.5)$ & $8(4.4)$ & $\begin{array}{l}\chi 2=0.239 \\
P=0.8874\end{array}$ \\
\hline
\end{tabular}

The effect of pregnancy complications on the delivery period is presented in Table 2. The highest number of pregnancy complications was found in Group 3. The main risk factors for PB were preeclampsia of varying severity, placental abruption, placental insufficiency, and fetal growth retardation.

The method of delivery depended on the mechanism of PB. In Group 1, vaginal delivery prevailed; in Group 2, cesarean section was performed on every third woman; in Group 3, the operation was performed in more than half of the cases.

In the world today, there is an increase in the number of iatrogenic PBs with a simultaneous decrease in the frequency of spontaneous PB..$^{(9,10)}$ It was found that in nulliparous women, $\mathrm{PB}$ is more common in the period of 22-37 weeks; the main reason is medical indications.

\section{Table 2.}

\section{Complications of pregnancy, $n(\%)$}

\begin{tabular}{|c|c|c|c|c|}
\hline Characteristics & $\begin{array}{l}\text { Group 1 } \\
(\mathrm{n}=32)\end{array}$ & $\begin{array}{l}\text { Group 2 } \\
(\mathrm{n}=115)\end{array}$ & $\begin{array}{c}\text { Group } 3 \\
(n=180)\end{array}$ & Statistics \\
\hline Polyhydramnios & - & $6(5.2)$ & $21(11.7)$ & $\begin{array}{l}\chi 2=7.045 \\
P=0.0296\end{array}$ \\
\hline Placental insufficiency & $2(6.2)$ & $5(4.3)$ & $56(31.1)$ & $\begin{aligned} \chi 2 & =36.177 \\
P & =0.0000\end{aligned}$ \\
\hline Fetal growth retardation & $4(12.5)$ & $15(13.0)$ & $57(31.7)$ & $\begin{aligned} \chi_{2}^{2} & =15.936 \\
P & =0.0003\end{aligned}$ \\
\hline Moderate preeclampsia & - & $1(0.87)$ & $32(17.8)$ & $\begin{aligned} \chi 2 & =26.091 \\
P & =0.0000\end{aligned}$ \\
\hline Severe preeclampsia & - & - & $36(20)$ & $\begin{aligned} \chi 2 & =33.037 \\
P & =0.0000\end{aligned}$ \\
\hline Urinary tract infections & $3(9,3)$ & $11(9,6)$ & $30(16,7)$ & $\begin{array}{l}\chi 2=3.546 \\
P=0.1698\end{array}$ \\
\hline Placenta previa & - & $4(3.5)$ & $7(3.9)$ & $\begin{array}{l}\chi 2=1.271 \\
P=0.5297\end{array}$ \\
\hline Placental abruption & - & $2(1.7)$ & $22(12.2)$ & $\begin{array}{c}\chi 2=14.148 \\
P=0.0008\end{array}$ \\
\hline Rh-negative blood & $1(3.1)$ & $11(9.6)$ & $28(15.6)$ & $\begin{array}{l}\chi 2=5.086 \\
P=0.0786\end{array}$ \\
\hline C-Section & $1(3.1)$ & $35(30.4)$ & $110(61.1)$ & $\begin{array}{c}\chi 2=51.466 \\
P=0\end{array}$ \\
\hline
\end{tabular}

The short cervix has been identified as a significant predictor of $\mathrm{PB}$. $^{(1)}$ The risk of $\mathrm{PB}$ is inversely proportional to the length of the cervix: the shorter the cervix, the higher the risk of PB and vice versa. Transvaginal cervicometry is an effective method for assessing the risk of PB. ${ }^{(12-16)}$ For this group, treatment methods include the use of progesterone or mechanical intervention, such as cerclage. ${ }^{(17)}$

For the prevention of iatrogenic PB, methods developed primarily for preeclampsia should be used. Preeclampsia is a serious pregnancy complication that not only determines maternal mortality, but is also associated with $\mathrm{PB}$ and prematurity. ${ }^{(18,19)}$ For iatrogenic $\mathrm{PB}$, which is largely mediated by preeclampsia, prophylactic low-dose aspirin reduces premature preeclampsia by $40 \%$ in women at higher risk. ${ }^{(20,21)}$

In conclusion, PB in nulliparous women occurs more often in the period of 34-37 weeks, the main reason being medical indications (maternal or fetal).

While greater clarity is needed, efforts to coordinate the prevention of both PB and preeclampsia, even if they are imperfect, are critical as part of any program to maximize maternal safety. Attempts to analyze, interpret, and reduce the level of PB should be considered separately, depending on the mechanism of their occurrence. These data can serve as a basis for changing health policy and clinical decisions on 
the prevention of PB and related adverse outcomes. Further research is needed to determine the most effective measures, and not just progesterone, to reduce PB.

\section{Competing Interests} interests

The authors declare that they have no competing

\section{References}

1. Vogel JP, Chawanpaiboon S, Moller AB, Watananirun K, Bonet M, Lumbiganon P. The global epidemiology of preterm birth. Best Pract Res Clin Obstet Gynaecol. 2018 Oct;52:3-12. doi: 10.1016/j.bpobgyn.2018.04.003.

2. Purisch SE, Gyamfi-Bannerman C. Epidemiology of preterm birth. Semin Perinatol. 2017 Nov;41(7):387-391. doi: 10.1053/j.semperi.2017.07.009.

3. Koullali B, van Zijl MD, Kazemier BM, Oudijk MA, Mol BWJ, Pajkrt E, Ravelli ACJ. The association between parity and spontaneous preterm birth: a population based study. BMC Pregnancy Childbirth. 2020 Apr 21;20(1):233. doi: 10.1186/s12884-020-02940-w.

4. Son M, Miller ES. Predicting preterm birth: Cervical length and fetal fibronectin. Semin Perinatol. 2017 Dec;41(8):445451. doi: 10.1053/j.semperi.2017.08.002.

5. Volkov V.G., Chursina O.V. A role of comprehensive cervix assessment in the first trimester of pregnancy for predicting preterm delivery. Obstetrics, Gynecology and Reproduction. 2020;14(2):174-181. doi: 10.17749/23137347/ob.gyn.rep.2020.094. [Article in Russian].

6. Romero R, Dey SK, Fisher SJ. Preterm labor: one syndrome, many causes. Science. 2014Aug 15;345(6198):7605. doi: $10.1126 /$ science. 1251816 .

7. American College of Obstetricians and Gynecologists' Committee on Practice Bulletins-Obstetrics. Practice Bulletin No. 172: Premature Rupture of Membranes. Obstet Gynecol. 2016 Oct;128(4):e165-77. doi: 10.1097/ AOG.0000000000001712.

8. Cunningham FG, Leveno KJ, Bloom SL, Hauth JC, Gilstrap LC III, Wenstrom KD. Williams obstetrics. 22nd ed. New York (NY): McGraw-Hill Medical Publishing Division; 2005.

9. Grétarsdóttir ÁS, Aspelund $\mathrm{T}$, Steingrímsdóttir $\mathrm{P}$, Bjarnadóttir RI, Einarsdóttir K. Preterm births in Iceland 1997-2016: Preterm birth rates by gestational age groups and type of preterm birth. Birth. 2020 Mar;47(1):105-114. doi: 10.1111/birt.12467.

10. Lucovnik M, Bregar AT, Steblovnik L, Verdenik I, Gersak $\mathrm{K}$, Blickstein I, Tul N. Changes in incidence of iatrogenic and spontaneous preterm births over time: a population-based study. J Perinat Med. 2016 Jul 1;44(5):505-9. doi: 10.1515/ jpm-2015-0271.

11. Hezelgrave NL, Watson HA, Ridout A, Diab F, Seed PT, Chin-Smith E, Tribe RM, Shennan AH. Rationale and design of SuPPoRT: a multi-centre randomised controlled trial to compare three treatments: cervical cerclage, cervical pessary and vaginal progesterone, for the prevention of preterm birth in women who develop a short cervix. BMC Pregnancy Childbirth. 2016 Nov 21;16(1):358. doi: 10.1186/s12884-0161148-9.

12. Volkov VG., Chursina OV. Ultrasound assessment of cervical length in the first trimester of pregnancy to predict preterm birth. International Journal of Biomedicine. 2018; 8(4):321-323. doi: 10.21103/Article8(4)_OA10

13. Conde-Agudelo A, Romero R, Hassan SS, Yeo L. Transvaginal sonographic cervical length for the prediction of spontaneous preterm birth in twin pregnancies: a systematic review and metaanalysis. Am J Obstet Gynecol. 2010 Aug;203(2):128.e1-12. doi: 10.1016/j.ajog.2010.02.064.

14. Lim AC, Hegeman MA, Huis In 'T Veld MA, Opmeer $\mathrm{BC}$, Bruinse HW, Mol BW. Cervical length measurement for the prediction of preterm birth in multiple pregnancies: a systematic review and bivariate meta-analysis. Ultrasound Obstet Gynecol. 2011 Jul;38(1):10-7. doi: 10.1002/uog.9013. 15. Barros-Silva J, Pedrosa AC, Matias A. Sonographic measurement of cervical length as a predictor of preterm delivery: a systematic review. J Perinat Med. 2014 May;42(3):281-93. doi: 10.1515/jpm-2013-0115.

16. Conde-Agudelo A, Romero R. Predictive accuracy of changes in transvaginal sonographic cervical length over time for preterm birth: a systematic review and metaanalysis. Am J Obstet Gynecol. 2015 Dec;213(6):789-801. doi: 10.1016/j. ajog.2015.06.015.

17. Berghella V, Mackeen AD. Cervical length screening with ultrasound-indicated cerclage compared with historyindicated cerclage for prevention of preterm birth: a metaanalysis. Obstet Gynecol. 2011 Jul;118(1):148-155. doi: 10.1097/AOG.0b013e31821fd5b0.

18. Volkov VG, Granatovich NN, Survillo EV, Cherepenko OV. Retrospective analysis of maternal mortality in preeclampsia and eclampsia. Rossiyskiy Vestnik AkusheraGinekologa. 2017;3:4-8. doi: 10.17116/rosakush20171734-8 [Article in Russian].

19. Jayaram A, Collier CH, Martin JN. Preterm parturition and pre-eclampsia: The confluence of two great gestational syndromes. Int J Gynaecol Obstet. 2020 Jul;150(1):10-16. doi: 10.1002/ijgo.13173.

20. Bramham K, Parnell B, Nelson-Piercy C, Seed PT, Poston L, Chappell LC. Chronic hypertension and pregnancy outcomes: systematic review and meta-analysis. BMJ. 2014 Apr 15;348:g2301. doi: 10.1136/bmj.g2301.

21. Hoffman MK, Goudar SS, Kodkany BS, Metgud M, Somannavar M, Okitawutshu J, Lokangaka A, Tshefu A, Bose CL, Mwapule A, Mwenechanya M, Chomba E, Carlo WA, Chicuy J, Figueroa L, Garces A, Krebs NF, Jessani S, Zehra F, Saleem S, Goldenberg RL, Kurhe K, Das P, Patel A, Hibberd PL, Achieng E, Nyongesa P, Esamai F, Liechty EA, Goco N, Hemingway-Foday J, Moore J, Nolen TL, McClure EM, Koso-Thomas M, Miodovnik M, Silver R, Derman RJ; ASPIRIN Study Group. Low-dose aspirin for the prevention of preterm delivery in nulliparous women with a singleton pregnancy (ASPIRIN): a randomised, double-blind, placebocontrolled trial. Lancet. 2020 Jan 25;395(10220):285-293. doi: 10.1016/S0140-6736(19)32973-3. Erratum in: Lancet. 2020 Mar 21;395(10228):e53. 